Research Article

\title{
Design and Development of a Mobile Robot for Search and Rescue Operations in Debris
}

\author{
Yakupcan Baldemir ${ }^{a * *}$, Soner Iyigün ${ }^{a}$ (D), Oruj Musayev ${ }^{a}$ (D), Cenk Ulu ${ }^{a}$ (D) \\ ${ }^{a}$ Department of Mechatronics Engineering, Ylldiz Technical University, 34353 Besiktas, Istanbul, Turkey
}

\begin{tabular}{l}
\hline ARTICLE INFO \\
\hline Article history: \\
Received 27 September 2020 \\
Accepted 11 October 2020 \\
\hline Keywords: \\
Communication Unit \\
Debris \\
Remote Control \\
Robot \\
Search and Rescue
\end{tabular}
\begin{abstract}
After an earthquake, critical tasks during the search and rescue operations are to quickly detect the locations of victims and recover them. Additionally, effective communication between responders in the field and the emergency management center is also important to provide successful operations. All these tasks are mostly performed by humans and trained dogs in dangerous and risky situations. In this study, the design and development of a mobile search and rescue robot are presented. The design criteria are determined based on operational requirements and stakeholder expectations. Considering the specified design criteria, the mechanical and electrical designs of the mobile robot are performed and corresponding control, communication, and user interface software are developed. Designed parts of the robot are manufactured and the system integration is done. Then robot functionality tests are performed. The test results show that the performance of the developed search and rescue robot meets the desired performance criteria. The developed search and rescue robot has great potential to provide an efficient way to reduce losses of lives by decreasing operation time and for getting accurate information about the situation of the disaster area.
\end{abstract}

This is an open access article under the CC BY-SA 4.0 license. (https://creativecommons.org/licenses/by-sa/4.0/)

\section{Introduction}

Today, mobile robots are widely used in many fields. One of the important application areas of mobile robots is the search and rescue operations. These robots continue to replace traditional search and rescue equipment in various applications, especially in the last 20 years.

In history, unfortunate disasters comparable to the Mexico City earthquake in 1985, the capital of Oklahoma bombing in 1995, and therefore the World Trade Center attacks on September 11, 2001 show that robots are required to help search and rescue teams in insecure and out of reach places. 135 rescuers died within the Mexico City earthquake. 65 of these died as they struggled to save rescue workers trapped in a narrow space [1]. The first real test and application of search and rescue robots are performed after the terrorist attack on the World Trade Center (WTC). In WTC, robots are used to explore these areas by transferring real-time display to saviors from an inaccessible surrounding.

Today, with the improvement of sensor technology and a rising in the speed and capacity of microcontrollers, robots that are small-scale enough to pass through rubble piles can be evolved [2]. There are various research fields for search and rescue robots such as mapping, victim detection [3], navigation, and exploration [4].

In literature, there are different types of search and rescue robots. One of these has a double-track wheel system, RC remote control, and various sensors [5]. The other, known as SALVOR, has six wheels locomotion system and can operate in autonomous and semiautonomous modes [6]. The operation of SALVOR relies on the data from its sensors about the environment and directions from the human operators. Another robotic system is aimed to widen a narrow gap and open a new space to unleash buried survivors from pressure as temporary supports [7]. Also, the robot can create areas for operating and moving courses for other rescue robots 
and tools. This robot consists of a spreader tool and a mobile unit. The spreader tool driven by a hydraulic actuator can spread the gap from 3 centimeters to 20 centimeters with $1000 \mathrm{~kg}$ payload.

In this study, the development of a mobile robot for search and rescue operations in debris is presented. This robot provides direct intervention to the wreckage region where the working of people and dogs is dangerous. In this way, the search operation time can be decreased. The robot is designed, manufactured, and integrated. Then, the functional tests are performed successfully and it is shown that the desired design criteria are met. The mobile robot has a four-wheel drive system. The camera is integrated into the system for navigation purpose and to facilitate human detection in debris. Additionally, it is equipped with temperature and gas sensors to measure temperature and detect gas leaks in the disaster area. The designed robot is remotely operated and able to move in the narrow gaps. All sensor data and video stream can be monitored via the user interface. Furthermore, the robot provides voice communication between search and rescue operator and victims. It can also be used to deliver water and basic foodstuffs to the casualty when necessary.

Today, preparation and operations take a long time in current search and rescue efforts. Special users and training are required for the use of existing robots on the market. Communication with the victim is not possible with existing robots. Unlike the existing robots, our study has the opportunity to communicate with the casualty. Besides, the robot is able to continue its movement if it encounters an obstacle while moving and turns over. The robot has a thermal camera to locate the victims under the wreckage and direct the search and rescue teams there more quickly.

\section{System Design}

\subsection{Design Requirements}

The design criteria are specified based on operational requirements and stakeholders' expectations such as AFAD (Ministry of Interior Disaster and Emergency Management Presidency). The determined design requirements and functional requirements are shown in Table 1 and Table 2, respectively.

Table 1. Design requirements

\begin{tabular}{|c|c|}
\hline Requirement & Value \\
\hline Maximum Weight & $3 \mathrm{~kg}$ \\
\hline $\begin{array}{c}\text { Maximum } \\
\text { Dimensions }\end{array}$ & $300 \times 300 \times 120 \mathrm{~mm}$ \\
\hline $\begin{array}{c}\text { Minimum wireless } \\
\text { communication distance }\end{array}$ & $50 \mathrm{~m}$ \\
\hline Voltage level & $12 \mathrm{VDC}$ \\
\hline Minimum operation time & $30 \mathrm{dk}$ \\
\hline
\end{tabular}

Table 2. Functional requirements

\begin{tabular}{|c|c|c|}
\hline Function & Requirement & $\begin{array}{l}\text { Covering the } \\
\text { Requirement }\end{array}$ \\
\hline Function 1 & Ability to operate in the dark & Lighting \\
\hline Function 2 & $\begin{array}{l}\text { Having a short turning } \\
\text { radius }\end{array}$ & $\begin{array}{l}\text { Four-wheel } \\
\text { drive system }\end{array}$ \\
\hline Function 3 & $\begin{array}{l}\text { Detection of unconscious } \\
\text { victims }\end{array}$ & Thermal camera \\
\hline Function 4 & $\begin{array}{l}\text { Ability to communicate } \\
\text { with disaster victim }\end{array}$ & $\begin{array}{l}\text { Microphone, } \\
\text { speaker }\end{array}$ \\
\hline Function 5 & Gas leak detection & Gas sensor \\
\hline Function 6 & $\begin{array}{l}\text { Image transfer, recording and } \\
\text { monitoring of system data }\end{array}$ & $\begin{array}{l}\text { User interface, } \\
\text { camera }\end{array}$ \\
\hline
\end{tabular}

\subsection{System Architecture}

The system architecture of the robot is determined as shown in Fig.1 considering the design and functional requirements.

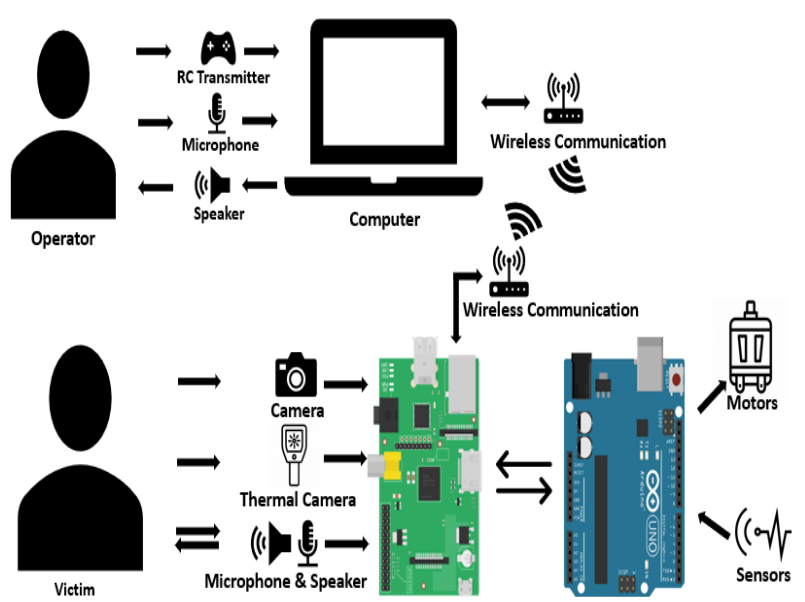

Figure 1. System Architecture

The search and rescue operator can control the robot with the RC controller unit and monitor all system data and the condition of the debris area via the user interface of the robot. Wireless communication is preferred between the operator panel and the robot [8]. The operator has the opportunity to talk to the victims in the wreckage region through the loudspeaker and microphone on the robot. In addition to these, thanks to sensors on the robot, operational data such as gas density and temperature values in the debris region can be monitored on the user interface [9].

\subsection{Mechanical Design}

The system mechanical design is shown in Fig. 2. To increase maneuverability, the robot uses a four-wheel drive system. DC motor is preferred as a drive motor. The robot chassis is positioned so as not to exceed the height of the wheel. In this way, the robot can continue its operation even when it turns upside down [10]. This also contributes to the protection of the chassis from collisions. ABS material is chosen as the chassis material. 
The placement of the equipment in the robot body is shown in Fig. 3.

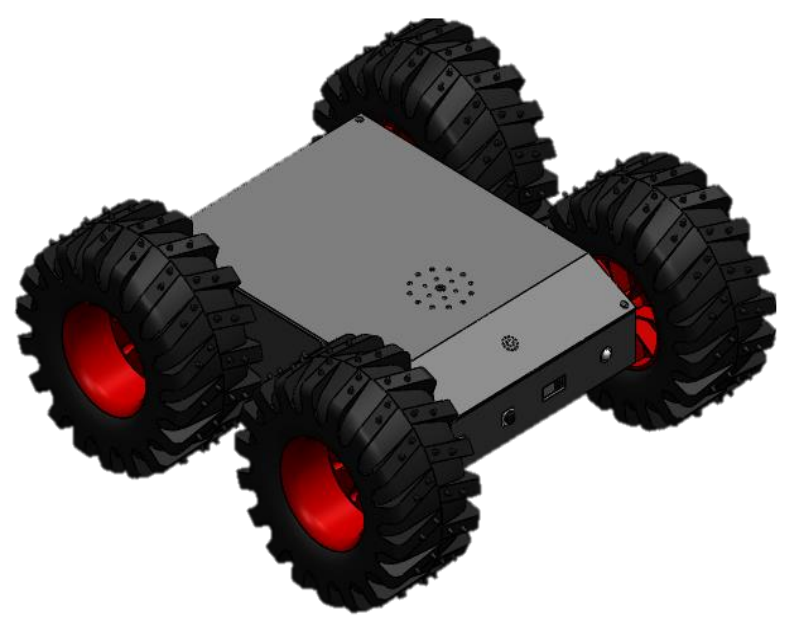

Figure 2. System Mechanical Design

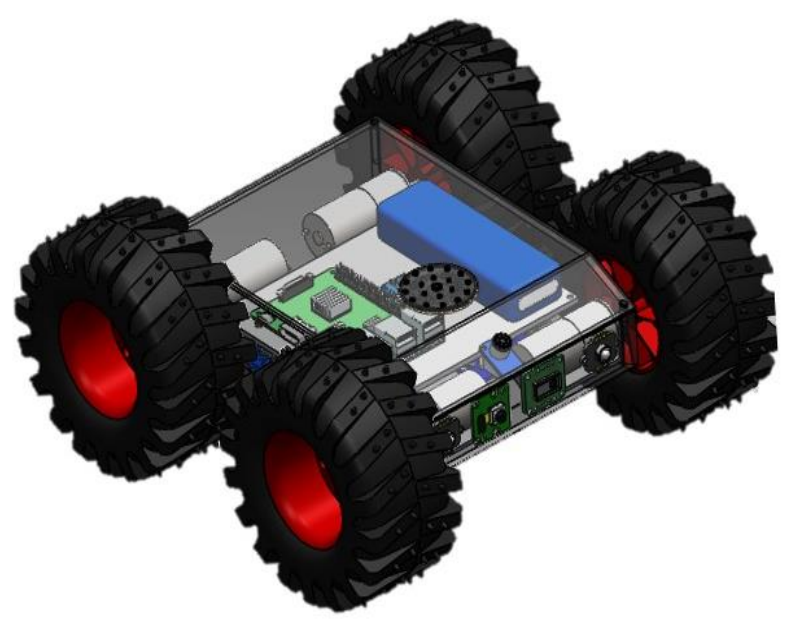

Figure 3. Internal placement of equipment

\subsection{Electrical Design}

Considering the robot's weight, acceleration value, nominal speed, and sloping areas, a 12V $210 \mathrm{rpm}$ DC motor with gearbox is determined as the robot wheel motor. A motor driver suitable for this motor is used. Raspberry Pi 4 2GB - Model B is chosen as the main processor of the robot. Transfer of images from the cameras to the operator instantly is provided through this processor. In addition, general data communication between the robot and the operator computer is provided through this card. Arduino Mega 2560 R3 is used for controlling DC motors and collecting sensor data.

Raspberry Pi Camera Module is preferred to enable the robot to provide live video stream from the debris area. In addition to this camera, the Adafruit AMG8833 IR Thermal Camera card has been used to enable the robot to detect victims in areas of debris that the operator cannot recognize. USB Dongle is preferred in the robot's communication system to increase the communication distance. 10DOF LSM303D sensor is used to measure the orientation, heading angle, and 3 axis acceleration values of the robot. The MQ-9 gas sensor board is used for the measurement of carbon monoxide and combustible gases, and the DHT11 sensor module for measuring the temperature and humidity. In addition, D40D50R speaker and MAX4466 Electret Microphone Module are preferred in order to enable the operator to communicate with the survivors in the wreckage area. The power requirement of all subsystems of the robot is calculated and $11.1 \mathrm{~V} 3 \mathrm{~S} 6000 \mathrm{mAh} \mathrm{Li}$-po battery is used as the power source.

\subsection{User Interface Design}

The user interface of the robot is shown in Fig. 4. The user interface enables the operator to use the robot effectively. Visual C\# programming language is preferred for the development of the user interface. In the developed interface, the operator can switch between the thermal camera and normal camera. By using this interface, the lights on the robot can be controlled. The operator is warned in case of any gas leakage hazard. It is also possible to communicate with victims via the user interface. In addition, all system data such as temperature, gas density, and robot orientation data can be monitored on the developed interface.

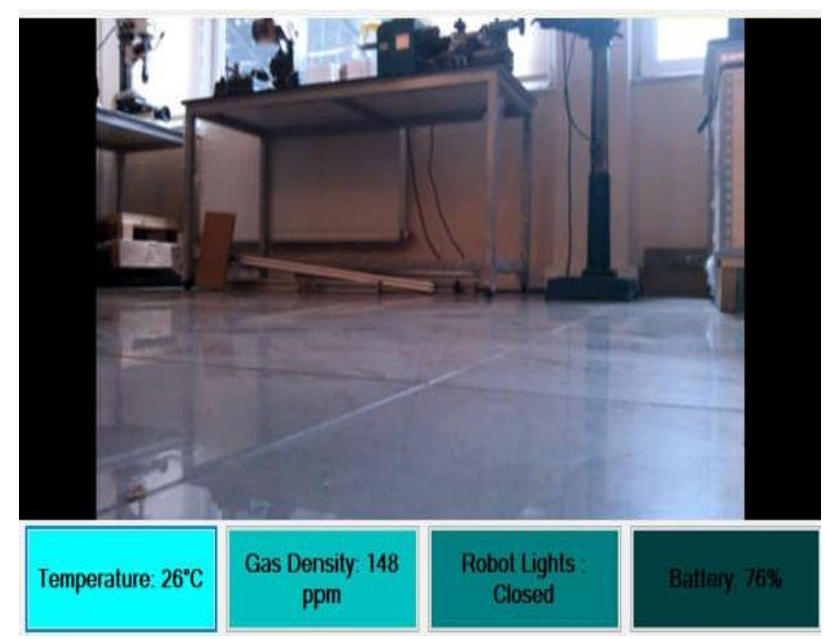

Figure 4. User Interface

\section{System Integration and Functional Tests}

After completing the system design, the mechanical parts of the robot are produced. The chassis of the robot is produced in 3D printer using ABS material. The produced chassis and the robot whose integration is completed are shown in Fig. 5 and Fig. 6, respectively. 


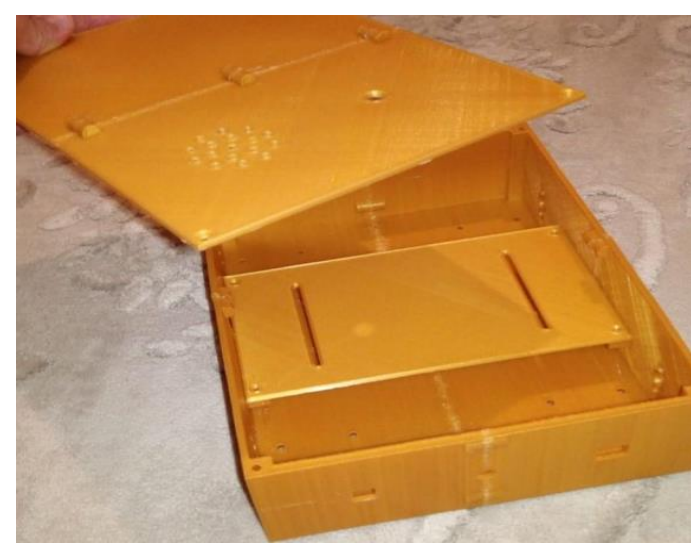

Figure 5. Produced Robot Chassis

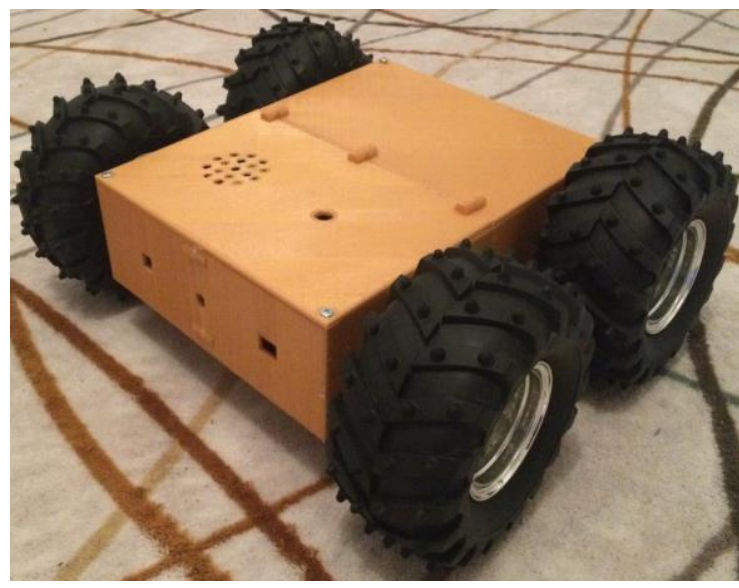

Figure 6. Search and Rescue Robot

After the system integration is completed, the functional tests of the robot are performed. Applied functional tests and obtained results are given in Table 3. As it is seen from the test results, the developed search and rescue robot meets all design criteria. Sample images from the functional tests are given in Fig. 7 and Fig. 8.

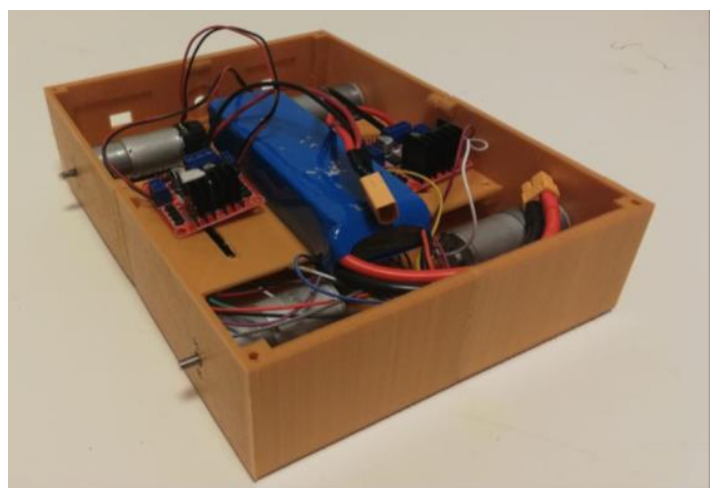

Figure 7. Sample Image from Functional Tests (1)

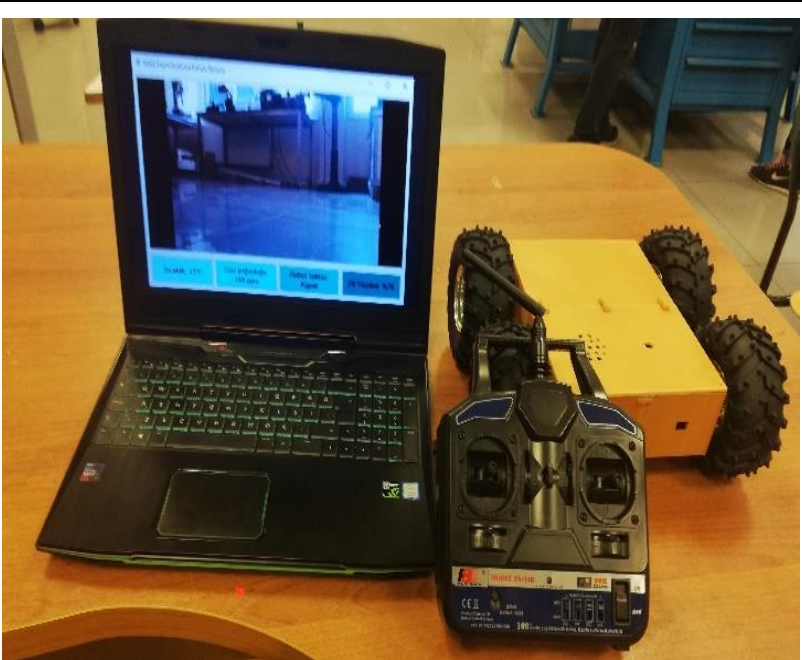

Figure 8. Sample Image from Functional Tests (2)

Table 3. Functional test results

\begin{tabular}{|c|c|}
\hline Functional test & Test result \\
\hline Communication test & $\begin{array}{l}\text { Communication at a distance of } 400 \mathrm{~m} \text { in the } \\
\text { open area is provided uninterruptedly. } \\
\text { In the building, communication is provided from } \\
\text { a distance of at least } 30 \mathrm{~m} \text {. }\end{array}$ \\
\hline Motion test & $\begin{array}{l}\text { The robot is successfully performed the given } \\
\text { motion commands. } \\
\text { The robot continues its movement when it turns } \\
\text { upside down. }\end{array}$ \\
\hline User interface test & $\begin{array}{l}\text { The acquisition of images from the camera and } \\
\text { the transfer of the data received by the sensors to } \\
\text { the interface are successfully completed. }\end{array}$ \\
\hline $\begin{array}{l}\text { Min. operation } \\
\text { time }\end{array}$ & $30 \mathrm{~min}$. \\
\hline
\end{tabular}

\section{Conclusions}

In this study, the design and development of a mobile search and rescue robot are presented. The robot searches the victims in the wreckage area after the earthquake and also transfers the collected data about the wreckage area to the rescue team in realtime. The system has been designed, produced, and integrated. The functional test results show that the developed robot meets design criteria. Depending on its features, the developed robot can effectively be used in search and rescue operations. By using this robot, the search operation time can be reduced.

Unlike the other existing search and rescue robots, the developed robot provides the opportunity to communicate with the victims. Additionally, if the robot encounters an obstacle while moving and turns over, it is able to continue its movement. Furthermore, thanks to its thermal camera, victims in the wreckage can be located and search and rescue teams can be directed to the location faster by using this information.

In future studies, it is planned to add the features of autonomous control and casualty detection by image processing to the system in order to increase the 
efficiency of the robot.

\section{Author's Note}

Abstract version of this paper was presented at 9th International Conference on Advanced Technologies (ICAT'20), 10-12 August 2020, Istanbul, Turkey with the title of "Design and Development of a Mobile Robot for Search and Rescue Operations in Debris".

\section{Acknowledgment}

This work is supported by TÜBİTAK (Project No: 1139B411900495), Turkey.

\section{References}

[1] I. Casper, M. Micire and R Murphy, Issues in Intelligent Robots for such and Rescue, SPIE Ground Vehicle Technology II, 4: 41- 46, 2000.

[2] A. Davids, "Urban search and rescue robots: from tragedy to technology," Intelligent Systems, IEEE [see also IEEE Intelligent Systems and Their Applications], vol. 17, no. 2, pp. 81-83, 2002.

[3] S. Bahadori, L. Iocchi, D. Nardi, and G. Settembre, "Stereo vision based human body detection from a localized mobile robot," in Proceedings. IEEE Conference on Advanced Video and Signal Based Surveillance, 2005., 2005, pp. 499-504

[4] D. Calisi, A. Farinelli, L. Iocchi, and D. Nardi, "Autonomous navigation and exploration in a rescue environment," in Safety, Security and Rescue Robotics, Workshop, 2005 IEEE International, 2005, pp. 54-59.

[5] Tunwannarux, A., ve S. Hirunyaphisutthikul. "Design features and characteristics of a rescue robot", 1083-87, 2005. https://doi.org/10.1109/ISCIT.2005.1567056.

[6] A. Denker, Baykal Sarığlu, Yeşim Öniz, Murat Tümer, Emre Can Akgül, Hilal Merve Altuğ, Kenan Kural, "DESIGN AND IMPLEMENTATION OF A MOBILE SEARCH AND RESCUE ROBOT ”, 2017.

[7] Zhang, Guowei, Li Bin, Zhiqiang Li, Wang Cong, Handuo Zhang, Shang Hong, Hu Weijian, ve Zhang Tao. "Development of Robotic Spreader for Earthquake Rescue*”, 2014. https://doi.org/10.1109/SSRR.2014.7017679.

[8] K.Albert and Henry Y. K. Lau, Robot Assisted Emergency Search and Rescue System With a Wireless Sensor Network, International Journal of Advanced Science and Technology, Vol. 3, Pages 1-3, February, 2009.

[9] M. H. Zulkefli, K. A. Mohd Annuar, S. H. Johari, M. R. Mohamad Sapiee and S. Ahmad, "Graphical User Interface (GUI) Controlled Mobile Robot" in Journal of Advanced Research in Computing and Applications, Vol. 1, No. 1, pp. 42-49, 2015.

[10] Siciliano, Bruno, and Oussama Khatib, ed. Springer Handbook of Robotics. Cham: Springer International Publishing, 2016. https://doi.org/10.1007/978-3-319-32552-1 